STUDI

FRANCESI

\section{Studi Francesi}

Rivista quadrimestrale fondata da Franco Simone

170 (LVII | II) | 2013

Varia

\title{
Jean-Jacques Queloz, Philippe Soupault: écriture de soi et lecture d'autrui
}

\section{Tania Collani}

\section{(2) OpenEdition}

\section{Journals}

\section{Edizione digitale}

URL: https://journals.openedition.org/studifrancesi/3217

DOI: $10.4000 /$ studifrancesi.3217

ISSN: 2421-5856

\section{Editore}

Rosenberg \& Sellier

\section{Edizione cartacea}

Data di pubblicazione: 1 juillet 2013

Paginazione: 488-489

ISSN: 0039-2944

\section{Notizia bibliografica digitale}

Tania Collani, «Jean-Jacques Queloz, Philippe Soupault: écriture de soi et lecture d'autrui», Studi Francesi [Online], 170 (LVII | II) | 2013, online dal 30 novembre 2015, consultato il 01 février 2023. URL: http:// journals.openedition.org/studifrancesi/3217 ; DOI: https://doi.org/10.4000/studifrancesi.3217

Questo documento è stato generato automaticamente il 1 février 2023.

\section{(c) (i) (9)}

Creative Commons - Attribuzione - Non commerciale - Non opere derivate 4.0 Internazionale - CC BYNC-ND 4.0

https://creativecommons.org/licenses/by-nc-nd/4.0/ 


\title{
Jean-Jacques Queloz, Philippe Soupault: écriture de soi et lecture d'autrui
}

\author{
Tania Collani
}

\section{NOTIZIA}

JEAN-JACQUES QUELOZ, Philippe Soupault: écriture de soi et lecture d'autrui, Louvain-la-Neuve, L'Harmattan/Academia, 2012 («Au coeur du texte», 25), pp. 172.

1 Insegnante nel dipartimento di studi francesi dell'Università di Basilea, Jean-Jacques Queloz pubblica nel presente volume la sua tesi di abilitazione su Philippe Soupault, prolungando il suo interesse per la letteratura degli "esuli" del surrealismo, già palesato con la sua tesi di dottorato pubblicata nel 1999 da Champion, e intitolata Pour une poétique de Michel Leiris. "À cor et à cri”: du journal à l'œuvre.

Riflettendo la dualità proposta nel titolo del volume, Queloz prende in considerazione due aspetti della scrittura multiforme di Soupault: i testi di carattere autobiografico (giustificando quell'«écriture de soi») e i testi di carattere critico (che scaturiscono dalla «lecture d'autrui»). Volendo uscire dal circolo vizioso che riduce troppo spesso l'opera di Soupault ai Champs magnétiques, scritti "automaticamente" e a quattro mani con André Breton nel 1919, Queloz ritorna a più riprese sulla ricchezza generica dello scrittore, che fu drammaturgo, romanziere, novellista, poeta, critico letterario, cinematografico e d'arte.

3 A livello metodologico, Queloz ritorna spesso sui concetti di "genere", di "singolarità", di "poetica" e di "approccio genetico" senza attardarsi in una definizione teorica, ma limitandosi ad esplicitarne l'applicazione analitica nel caso preciso del suo corpus di testi. Per il genere si affida a Qu'est-ce qu'un genre littéraire (1989) di J.-M. Shaeffer; per la poetica e la singolarità, in quanto scelta che l'autore fa tra tutte quelle possibili, cita il Dictionnaire encyclopédique des sciences du langage (1972) di O. Ducrot et $\mathrm{T}$. Todorov; per la 
critica genetica fa allusione agli Éléments de critique génétique (1994) di A. Grésillon, specificando che il suo studio non si basa su testi manoscritti, bozze, annotazioni o su altri documenti preparatori, ma esclusivamente sulle diverse versioni dei testi pubblicati.

4 A livello di corpus, pur riconoscendo la difficoltà di separare il resoconto autobiografico dalla storia letteraria negli scritti di Soupault (p. 83), Queloz include nella prima parte del suo volume dedicata alla scrittura autobiografica: Déposition, Histoire d'un blanc, Apprendre à vivre 1897-1914, Mémoires de l'oubli 1914-1923, Mémoires de l'oubli. Histoire d'un blanc 1897-1927, Mémoires de l'oubli 1923-1926 - decidendo volontariamente di scartare i testi che riguardano gli anni successivi al 1926: Le Temps des assassins, Le Journal d'un fantôme e Mémoires de l'oubli 1927-1933. Per quanto riguarda la parte critica, il corpus si limita ai testi critici che Soupault dedica a Lautréamont, e che l'autore analizza partendo da nuclei tematici o formali (nel caso dell'analisi dello stile e della poetica della critica di Soupault) che si evolvono nel corso del tempo.

5 Con il presente volume, Queloz vuole dimostrare in che modo la scrittura critica e quella autobiografica di Soupault siano animate da una poetica comune, quella che l'autore riconduce più volte al Platone del dialogo tra Alcibiade e Socrate: l'altro come specchio di se stessi. È in questa relazione speculare che la lettura dell'altro diventa un'azione che fa tutt'uno con la scrittura del sé. 